\title{
Performance of Wind Pump Prototype
}

\author{
Mulu Bayray*, Hailay Kiros, Mohammedsalih Abdelkadir, Anwar Mustefa, Mesele \\ Hayelom, Asfafaw Haileselasie, Ashenafi Kebedom, Petros Gebray, Alemu Yemane, \\ Solomon T/Michael, Dawit Abay, Bariso Bino \\ Department of Mechanical Engineering, Ethiopian Institute of Technology-Mekelle (EiT-M), \\ Mekelle University, Mekelle, Ethiopia (*mul_at@yahoo.com).
}

\begin{abstract}
A wind pump prototype with $3.6 \mathrm{~m}$ rotor diameter, $19 \mathrm{~m}$ hub height above ground and $0.22 \mathrm{~mm}$ reciprocating pump stroke has been developed at the Department of Mechanical Engineering, Mekelle University. The prototype was designed and manufactured locally. Theoretical model based on combined efficiency of the rotor and the reciprocating pump was used to estimate the performance of the wind pump. One year wind speed data collected at $10 \mathrm{~m}$ height was extrapolated to the wind pump hub height using wind shear coefficient. The model assumed balanced rotor power and reciprocating pump, hence did not consider the effect of pump size. The theoretical model estimated the average daily discharge to be around $50 \mathrm{~m}^{3}$ and $30 \mathrm{~m}^{3}$ at $8 \mathrm{~m}$ and $12 \mathrm{~m}$ head, respectively.

The prototype was tested with the same pump stroke but two different size pumps at two different heads. The pumps were with internal diameter of 55 and $70 \mathrm{~mm}$ and the test heads were at 8 and $12 \mathrm{~m}$. Measurement of the flow rate, rotational speed and wind speed were made every 10 minutes during the test period. The data collected were analyzed to find the performance of the wind pump at the two test heads and two pump sizes. The flow rate data was plotted against binned wind speed data to determine the linear fit function. The linear fit function was then used to estimate the flow rate at any wind speed. With the $55 \mathrm{~mm}$ pump the measured average daily discharge was 20 and $19 \mathrm{~m}^{3}$ at $8 \mathrm{~m}$ and $12 \mathrm{~m}$ head, respectively. With the $70 \mathrm{~mm}$ pump the measured average daily discharge was $41 \mathrm{~m}^{3}$ and $30 \mathrm{~m}^{3}$ at $8 \mathrm{~m}$ and $12 \mathrm{~m}$ head, respectively.
\end{abstract}

Keywords: Wind pump, Windmill, Performance testing, Pump efficiency, Pump discharge, Ethiopia.

\section{INTRODUCTION}

Energy demand for water pumping has been growing in the country for both drinking water and irrigation. The source of energy for pumping in rural communities not connected to the national electricity grid has been mainly diesel fuel. Unfortunately, in rural places, where the houses are scattered over a large area the provision of power from the main power grid consume a lot of resources; consequently becomes unaffordable and expensive. On the other hand, wind energy could be harnessed directly as a means for mechanical drive or as an electrical source using low cost and affordable resources and can be a good alternative for the rural communities.

Recent wind energy resource studies indicate that the Northern and Eastern regions of Ethiopia have high resource potential (Mulugeta and Drake, 1996; SWERA, 2007; Hydrochina, 2012). 
The highlands of the Northern part near or along the escarpment of the rift valley are considered to be the areas with high potential for wind energy utilization. Detail localized wind energy resource assessment that could lead to implementation of the technology has been done for Geba catchment (Mulu et al., 2013).

The study reported in this paper was part of a project aimed at developing local capacity in design, manufacture and testing of wind pump technology. The design and manufacture of the prototype has been reported elsewhere (Mulu et al., 2012). This paper will focus on the performance test of a wind pump prototype.

\section{LITERATURE REVIEW}

Wind energy has been used for thousands of years for water pumping, grain milling, and other applications. Water pumping is one of the popular applications of wind energy. Recently a new interest has incited a revival of manufacturing of mechanical windmills with numerous new companies in the world introducing machines for the remote water pumping market. Wind pumps are economically becoming attractive and competitive with other conventional power sources for water supply. Hence development and use of wind pumps is expected to continue in the future.

Several methods are proposed to estimate the wind pump performance under fluctuating conditions of wind regimes (Mathew, 2006). Among which an integrated approach incorporating the characteristics of the rotor, pump and the wind regime, for defining the system performance has been found appropriate to model the wind pump. The theoretical model used in this paper has been based on the equations and relationships suggested in this reference.

The matching of wind pump and piston pump is of the utmost importance for a satisfactory performance. Choosing a large pump leads to a high output (volume of water pumped), but a low availability (i.e. the wind pump will often stand still) and the choice of a small pump improves availability but reduces output (Van Meel and Smulders, 1989). The optimal choice of the size of the piston pump depends on the wind regime: for strong winds one may use a larger pump than for weak winds. In matching a pump to a windmill, one needs to establish the best possible compromise between output and availability. 
Clark carried out performance test on two windmills with different rotor sizes $(2.44 \mathrm{~m}$ and $4.88 \mathrm{~m}$ diameter) with intention of comparing their performance (Clark, 1995). Identical pumps, pump rods, drop pipes, and equal tower height and all same measurement standards for both windmills have been used and found the larger windmill pumped more water (14,874 L/day) than smaller one (10,974 L/day). But it was found the larger one had a peak system efficiency of $6.5 \%$ which is much less than $10.5 \%$ for the smaller one. This experimental result reflects something that theoretical analysis and model wind tunnel analysis may not show us.

Clark and McCarty carried out a field test on two similar windmills under the same test condition but different pumps to check the effect of piston length on performance (Clark and McCarty, 1990). Fixed stroke standard pump and a hydraulic variable stroke pump were used. It was observed that there was no effect on the cut-in wind speed but at higher wind speed variable stroke pump yielded more water and its efficiency curve elevated smoothly and reached peak at about $10 \mathrm{~m} / \mathrm{s}$ and dropped down smoothly again. In contrast, efficiency of fixed stroke pump skipped to peak at $4 \mathrm{~m} / \mathrm{s}$ and dropped rapidly at speeds above $4 \mathrm{~m} / \mathrm{s}$. The study concluded that variable stroke hydraulic pump has better advantage over fixed stroke pump for single-acting piston pump windmills. The work also indicated that there is a need to choose a wind pump rotor and wind pump size combination for best efficiency and capacity.

\section{METHODOLOGY}

\subsection{Theoretical Model for Analysis of Performance of Wind Pump}

A method for predicting output of simple multi-bladed wind pump mechanically coupled to a piston pump was proposed by Mathew (2006). The proposed method adopts an integrated approach by considering the interaction between the rotor, pump and the wind regime to model the wind pump performance. In this approach the wind velocity-power relationship of the rotor was assumed to be quadratic and the wind regime was assumed to be characterized by the Rayleigh distribution. Differences in the starting and running torque requirements of the pump were also considered in the model.

The combined efficiency of rotor and pump $\left(\eta_{\text {overall }}\right)$ is given by the following equation:

$\eta_{\text {overall }}=4 C_{p} * \eta_{(t, p)}\left[1-K_{\odot}\left(\frac{V_{I}}{V}\right)^{2}\right] K_{\odot}\left(\frac{V_{I}}{V}\right)^{2}$ 
Where $C_{p}$ is rotor design power coefficient, $\eta_{(t, p)}$ is the combined transmission and pump efficiency, $\mathrm{K}_{\mathrm{o}}$ is a constant taking care of starting behavior of rotor-pump combination, $\mathrm{V}$ is the wind speed and $V_{I}$ is the cut-in wind speed.

The instantaneous power output of the wind pump $\left(\mathrm{P}_{\mathrm{V}}\right)$ at any speed $(\mathrm{V})$ was defined in terms of its characteristics at cut-in and design points by the following equation.

$P_{V}=2 C_{\mathrm{p}} * \eta_{(t, p)} * \rho_{\square} * A * V^{3}\left[1-K_{\odot}\left(\frac{V_{I}}{V}\right)^{2}\right] K_{\odot}\left(\frac{V_{I}}{V}\right)^{2}$

Where, $\rho_{\mathrm{a}}$ is the density of air and $\mathrm{A}$ is the swept area of the rotor.

The pumped water flow rate $\left(\mathrm{Q}_{V}\right)$ at any wind speed $(\mathrm{V})$ then can be given by:

$\dot{Q}_{V}=2 C_{p} * \eta_{(t, p)}\left[\frac{\rho_{a}}{\rho_{w}}\right]\left[\frac{A V^{3}}{g h}\right]\left[1-K_{o}\left(\frac{V_{I}}{V}\right)^{2}\right] K_{o}\left(\frac{V_{I}}{V}\right)^{2}$

Where, $\rho_{\mathrm{w}}$ is the density of water and $\mathrm{h}$ is the pumping head.

The average volume of water pumped for a period of time $(\mathrm{T})$ is approximated by the following equation.

$$
\begin{aligned}
Q_{T}=2 T C_{p} \eta_{(t, p)} & {\left[\frac{\rho_{\alpha}}{\rho_{w p}}\right]\left[\frac{A V_{o}^{3}}{g h}\right]\left[1-K_{\circ}\left(\frac{V_{I}}{V_{o}}\right)^{2}\right] K_{0}\left(\frac{V_{I}}{V_{o}}\right)^{2}\left[\frac{4 V_{m}^{2}}{\pi\left(V_{o}^{2}-V_{I}^{2}\right)}\left\{e^{-\frac{\pi}{4}\left(\frac{V_{I}}{V_{m}}\right)^{2}}-e^{-\frac{\pi}{4}\left(\frac{V_{o}}{V_{m}}\right)^{2}}\right\}\right.} \\
& \left.-\left(e^{-\frac{\pi}{4}\left(\frac{V_{o}}{V_{m}}\right)^{2}}\right)\right]
\end{aligned}
$$

In the above equations gravitational acceleration $(g)$, water density $\left(\rho_{\mathrm{w}}\right)$ and air density $\left(\rho_{\mathrm{a}}\right)$ are constants. Water head (h), Average Velocity (V) and time period (T) are known variables. Assumed values from the design are: a constant taking care of starting behavior of rotor-pump combination $\left(\mathrm{K}_{\mathrm{o}}\right)$ in the range of $(0.2-0.25)$, cut in velocity $\left(\mathrm{V}_{\mathrm{I}}\right)$ and cut out velocity $\left(\mathrm{V}_{\mathrm{O}}\right)$, coefficient of performance of rotor $\left(\mathrm{C}_{\mathrm{P}}\right)$ and transmission and pump efficiency $\eta(\mathrm{t}, \mathrm{p})$. The calculated values from the equations are: system efficiency, power output, water flow rate and total volume of water pumped per day.

One year wind data from Mekelle University metrological station (at $300 \mathrm{~m}$ distance from wind pump prototype) were analyzed and the system efficiency, power output, water flow rate and daily discharge were predicted using the above equations. The above equations with design input data and assumed data were executed in MATLAB software to obtain simulated results for a period of one year. 


\subsection{Performance Test of the Wind Pump Prototype}

The basic design specifications were: design wind speed $4.5 \mathrm{~m} / \mathrm{s}$ at $19 \mathrm{~m}$ above ground, design head $15 \mathrm{~m}$ and flow rate per day 16,000 liters. Most of the prototype components were manufactured in the Department workshop and some of the components were subcontracted to small workshops in Mekelle city.

Table 1. General description of the system.

\begin{tabular}{|lll|}
\hline Wind pump prototype & Type of pumping system & Mechanical wind pump \\
\hline & Year of installation & 2012 \\
\hline & Location of the prototype & Mekelle University main campus \\
\hline Rotor diameter & $3.6 \mathrm{~m}$ \\
\hline Number of blades & 18 \\
\hline Tower height & $19 \mathrm{~m}$ \\
\hline & Stroke of pump rod & $0.22 \mathrm{~m}$ \\
\hline Wind Mast & Control/safety system & Mechanical control (by hand) \\
\hline & Metrological station & Mekelle University main campus \\
\hline Height of measurement & $10 \mathrm{~m}$ \\
\hline & Instrument & Anemometer with data logger \\
\hline Exposure & Good \\
\hline
\end{tabular}

The prototype wind pump was erected in campus for testing (Table 1). Figure 1(a) shows a photograph of the wind pump system taken from the side. Figure 1(b) shows schematically the pumping system. It indicates the distance above a reference ground level of the water intake, the rotor, the mechanical transmission, the pump, the water storage tank and the water discharge pipe. Figure 1(c) shows a picture of the wind measurement mast.

The pumping performance test consists of continuous sets of measurements taken during ten minute time intervals. Measurements of time, wind speed, flow rate and stroke/ rotor rotation were taken in the same order every time. A total of over 130 sets of ten minute measurements were taken over a period of four to six days for each setup. The sets of measurements have covered periods when the wind speed is high as well as periods when the wind speed is low. The period, for which the rotor did not rotate at all during a 10-minute period, were omitted. Data collection on wind pump and pumping performance were carried out in the months of April June, 2013. The data collected included: Day and Time (hour, minute, second), Water flow rate 
(liters), Wind speed $(\mathrm{m} / \mathrm{s})$ and Wind pump rotor angular speed (rpm). The water flow rate, wind speed, and angular speed of the piston pump were recorded at 10-minute averages.

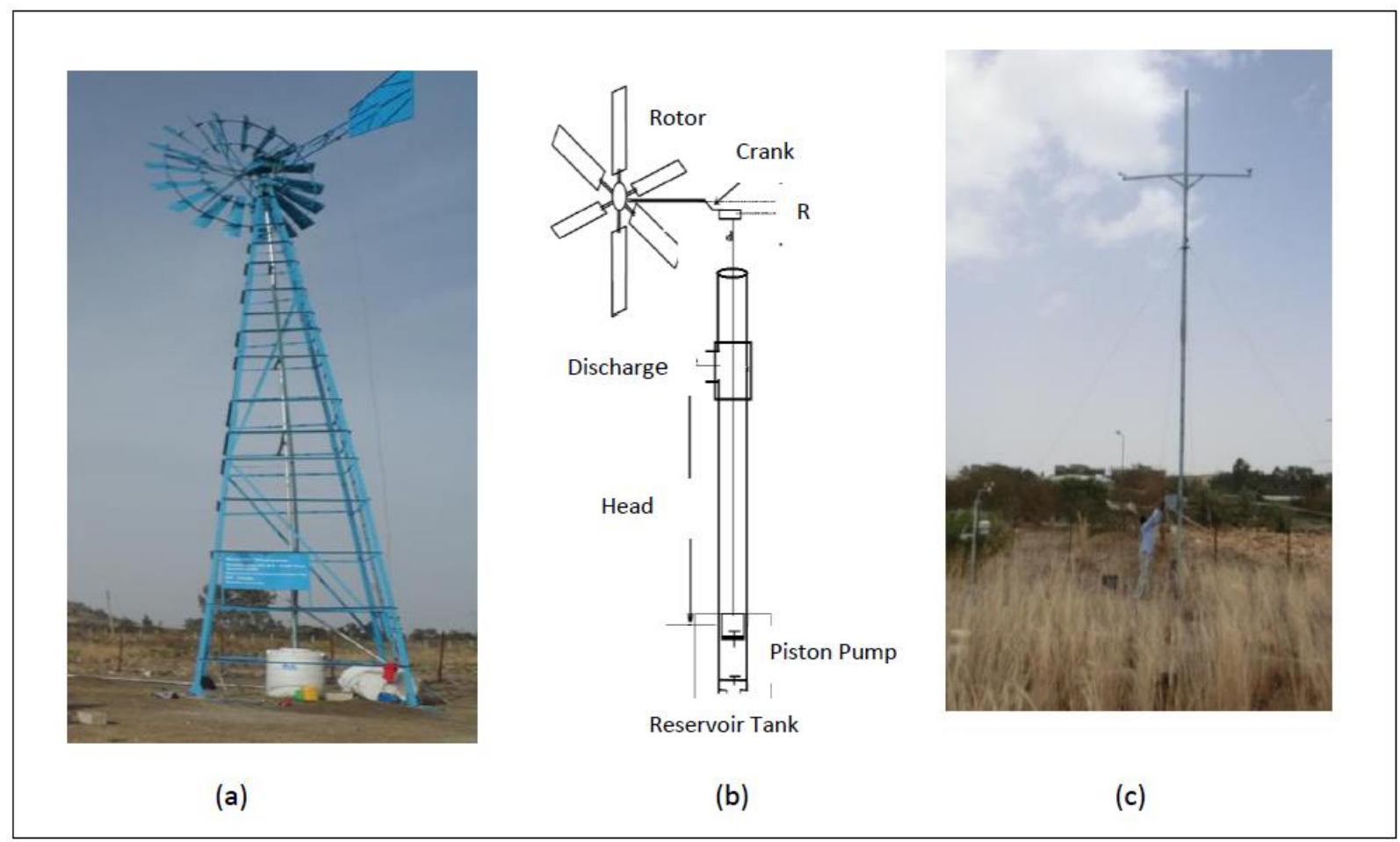

Figure 1a) Pictures of wind pump prototype, b) schematic diagram of the test setup and c) the wind measurement mast.

The performance test was done in four different setups with two different size pumps and two different heads. Setup 1 and 2 were with $55 \mathrm{~mm}$ pump at $8 \mathrm{~m}$ and $12 \mathrm{~m}$ head, respectively. Setup 3 and 4 were with $70 \mathrm{~mm}$ pump at $8 \mathrm{~m}$ and $12 \mathrm{~m}$ head, respectively.

The data collected was analyzed to evaluate the performance of the system. At least 10 records of ten-minute sample data were obtained in each $0.5 \mathrm{~m} / \mathrm{s}$ wind speed bin over the wind speed range of 2.5 to $9 \mathrm{~m} / \mathrm{s}$ for each test setup. Occasionally, startup times were recorded to estimate the cut in wind speed of the wind pump. The analysis of collected data involves:

- Data validation: all collected data were summarized using MATLAB software and glitches and outliers were eliminated from the data. The data were then binned with wind speed $(0.5 \mathrm{~m} / \mathrm{s}$ wind speed bins $)$.

- Average amount of daily water pumped for each pump and pump head were obtained. 
- Wind pump power curve and water flow rate as a function of wind speed binned at 0.5 $\mathrm{m} / \mathrm{s}$ were obtained using MATLAB.

- The average daily water supply of the pump for the wind speed history of Mekelle University was predicted using the experimental power curve.

- System efficiency curve and volumetric efficiency curve of piston pump at each wind speed bin for all testing setups were obtained.

Comparison of the theoretical values with the experimental results was done. The following parameters were compared:

- Performance of smaller pump versus larger pump.

- System efficiency and average daily water yield at $8 \mathrm{~m}$ depth versus $12 \mathrm{~m}$ depth for both pumps.

- Experimental system efficiency and average daily water yield versus design system efficiency and average daily water yield.

\section{DISCUSSION}

\subsection{Wind Data and Assumptions of Variables}

As discussed in the methodology section, wind data was taken from Mekelle University wind measurement mast. One year data from April 2010 up to May 2011 was used in the analysis. Equations 1-4 discussed previously were used to predict the overall efficiency, power and discharge rate. The values of the constants and assumed variables are shown in table 2 .

Table 2 Values of constants and assumed variables in the analysis.

\begin{tabular}{|c|c|c|}
\hline Variable & Recommended range & Value used in the analysis \\
\hline $\mathrm{Cp}$ & Design value & 0.35 \\
\hline$\eta_{(t, p)}$ & $70-80 \%$ & $75 \%$ \\
\hline Ko & $0.2-0.25$ & 0.23 \\
\hline $\mathrm{V}_{\mathrm{I}}$ & Design cut-in value & $2.5 \mathrm{~m} / \mathrm{s}$ \\
\hline $\mathrm{V}_{\mathrm{O}}$ & Design cut-out value & $12 \mathrm{~m} / \mathrm{s}$ \\
\hline $\mathrm{H}$ & & $\mathrm{h}_{1}=8 \mathrm{~m}, \mathrm{~h}_{2}=12 \mathrm{~m}$ \\
\hline$\rho_{\mathrm{a}}$ & & $0.995 \mathrm{~kg} / \mathrm{m}^{3}$ \\
\hline$\rho_{w w}$ & & $1000 \mathrm{~kg} / \mathrm{m}^{3}$ \\
\hline
\end{tabular}




\subsection{Theoretical Model Results}

\subsubsection{Overall system efficiency}

The overall system efficiency is found from equation 1. Figure 2 shows the result of the calculation for the overall system efficiency as a function of wind speed. The pump system shows high efficiency at lower wind speeds, the peak value is $20 \%$ at the cut-in speed. The efficiency continuously decreases with wind speed. This is expected from wind pumps with piston pumps. The efficiency decreases due to the effect of dynamic loading of the pump lift rod and mismatch between the characteristics of the rotor and the piston pump.

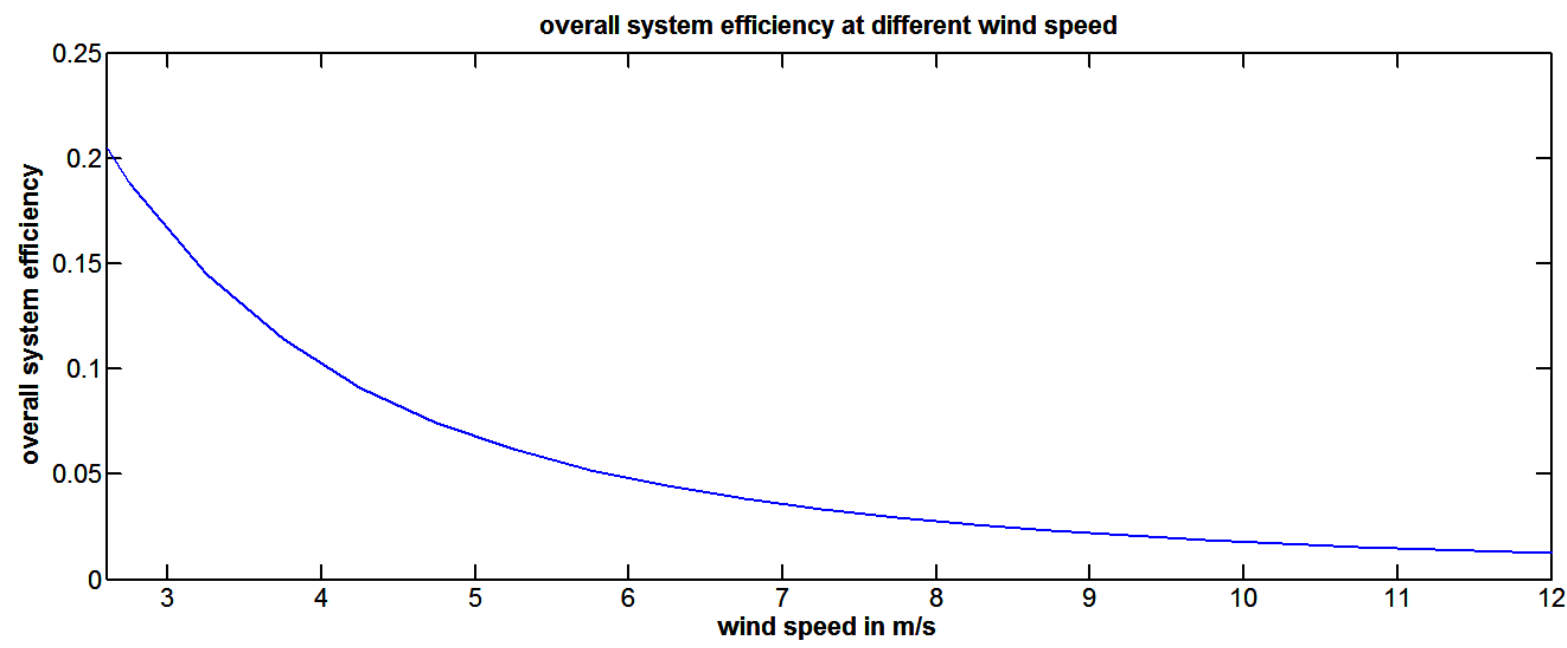

Figure 2. Overall system efficiency as a function of wind speed.

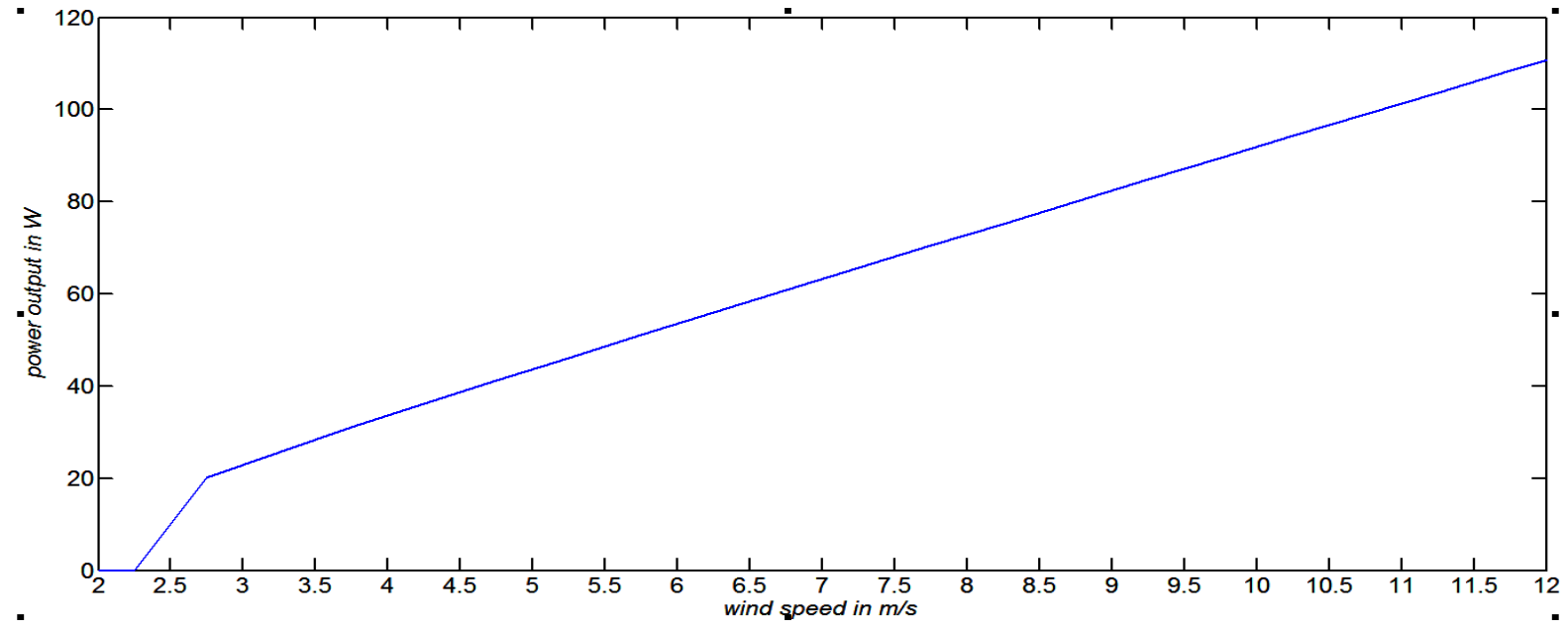

Figure 3. Wind pump power curve. 


\subsubsection{Wind pump power curve}

The wind pump power is given by equation 2. Figure 3 shows the plot of the wind pump power as a function of wind speed. It can be noticed that the power increases continuously up to the cut out wind speed since the conversion of wind energy is directly by mechanical motion without any power regulation. The maximum power goes up to $110 \mathrm{~W}$ at wind speed of $12 \mathrm{~m} / \mathrm{s}$. At the design wind speed of $4.5 \mathrm{~m} / \mathrm{s}$ the power is about $40 \mathrm{~W}$.

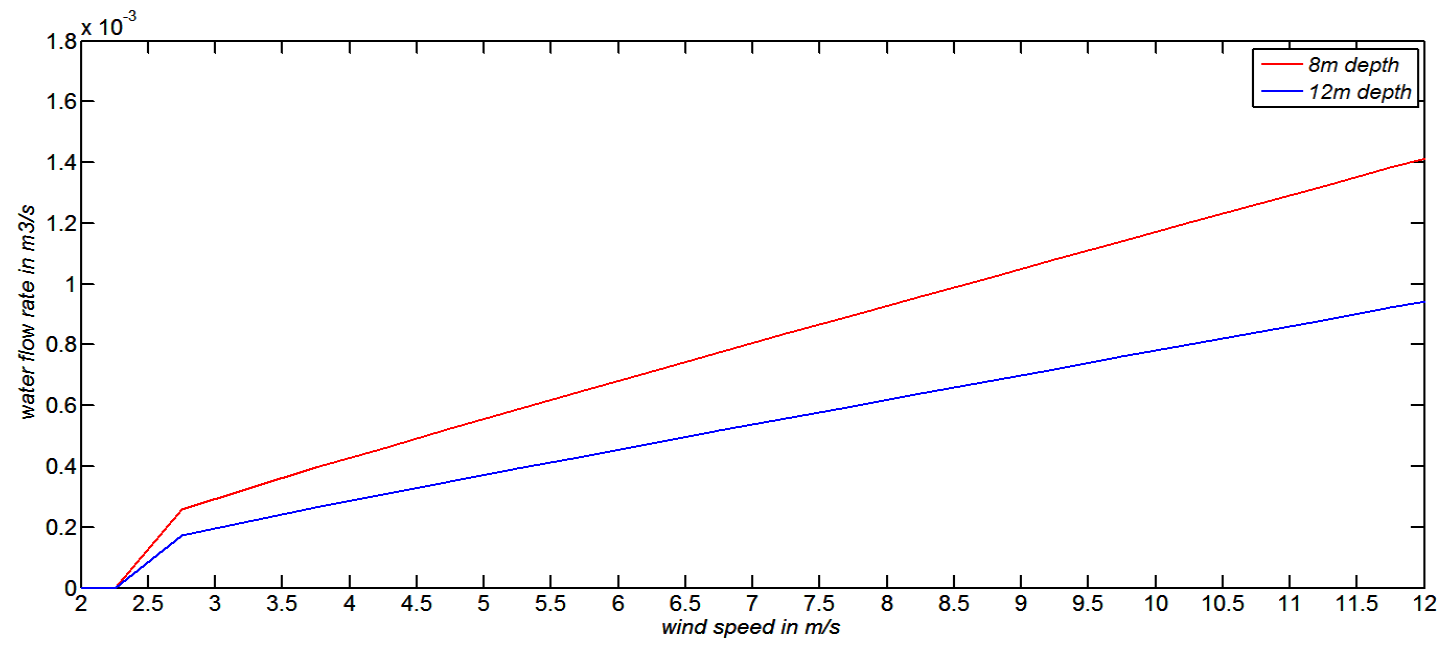

Figure 4. Water flow rate against wind speed.

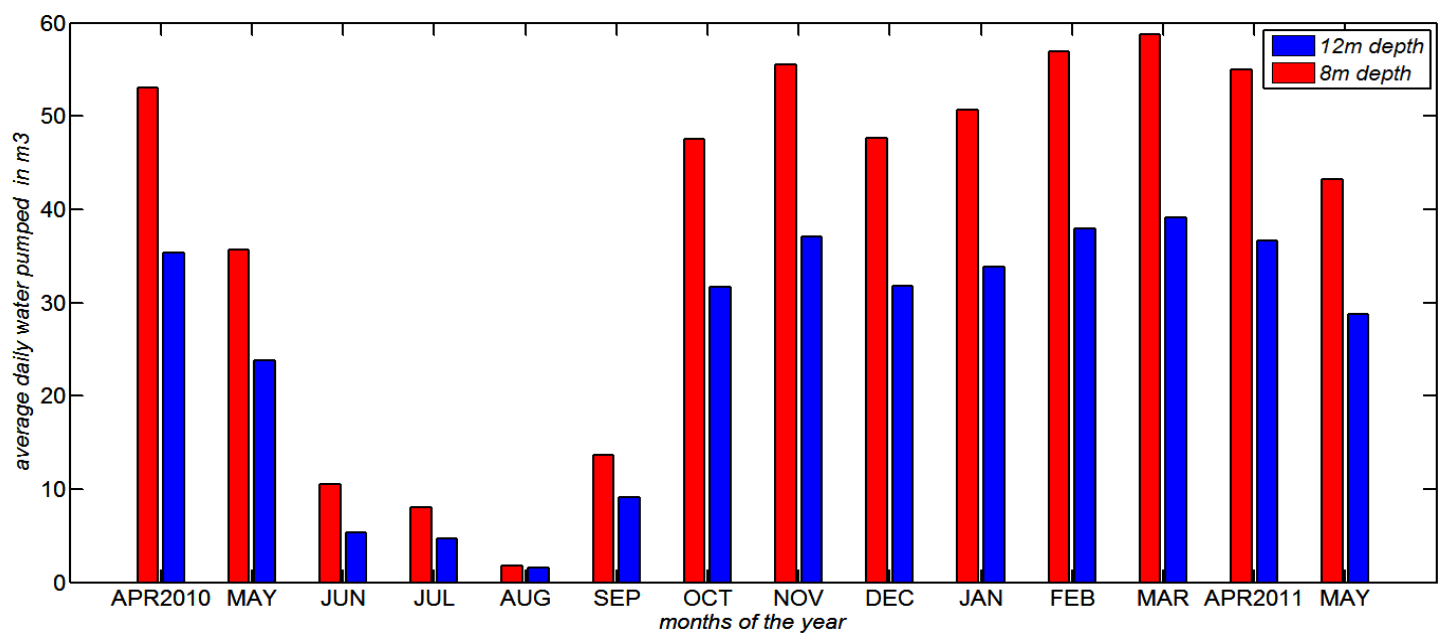

Figure 5. Daily average discharge for the months of the year.

\subsubsection{Water flow rate}

The water flow rate at given wind speed is found from equation 3 . The flow rate is calculated at discharge heads of $8 \mathrm{~m}$ and $12 \mathrm{~m}$. Figure 4 shows the flow rate against the wind speed which 
shows linear relationship with wind speed. The flow rate is higher at the head of $8 \mathrm{~m}$ than that of $12 \mathrm{~m}$. At the design wind speed of $4.5 \mathrm{~m} / \mathrm{s}$; the water flow rate is about $0.5 \mathrm{~m}^{3} / \mathrm{s}$ and $0.35 \mathrm{~m}^{3} / \mathrm{s}$ at $8 \mathrm{~m}$ and $12 \mathrm{~m}$ pumping depth, respectively.

\subsubsection{Daily average water discharge}

As wind speed is continuously changing and thus the rate of water being pumped changes with time, the average hourly, daily, weekly and monthly volume of water pumped becomes an important consideration. For domestic use and livestock drinking daily average volume of water pumped is very important. Monthly average is also equally important when irrigation is an issue. Daily water flow capacity is probably the best overall performance indicator of a wind pump system. The daily averaged discharge predicted using the one year wind data and employing equation 4 is shown in figure 5. The daily discharge is low during the rain months of June until September, where the wind pump may not be needed. In the remaining dry months the estimated average daily discharge was found to be around $50 \mathrm{~m}^{3}$ and $30 \mathrm{~m}^{3}$ at $8 \mathrm{~m}$ and $12 \mathrm{~m}$ head, respectively. The peak values are for the month of March with $60 \mathrm{~m}^{3}$ and $40 \mathrm{~m}^{3}$ for the $8 \mathrm{~m}$ and $12 \mathrm{~m}$ head, respectively.

\subsection{Experimental Results}

\subsubsection{Water flow rate with wind speed}

The flow rate at the corresponding wind speed was analyzed using bin size of $0.5 \mathrm{~m} / \mathrm{s}$. The average, minimum and maximum flow rates at each bin were calculated. A linear fit was found for the average flow rate. The results are shown in figure 6 for all the four setups. A very good linear fit was observed with the value of $\mathrm{R}^{2}$ greater than 0.97 . The linear fit equations for the respective setups were found as shown in the plots. To observe the scatter at each bin, the minimum and maximum values are also plotted. In setup 1 and 2 the scatter is low at low speed and increases with increase in speed. Larger scatter is observed in setup 3 and 4.

\subsubsection{Measured overall system efficiency}

The overall system efficiency calculated by using the actual water delivered is shown in figure 7 for the four setups. The actual measured efficiency is lower than that predicted theoretically in setup 1, 2 and 3. The efficiency plot shows that values closer to the theoretical prediction are found for setup 4 pump size $70 \mathrm{~mm}$ at head of $12 \mathrm{~m}$. This means that the assumptions made during the theoretical predictions are closer to the actual situation of setup 4 . 

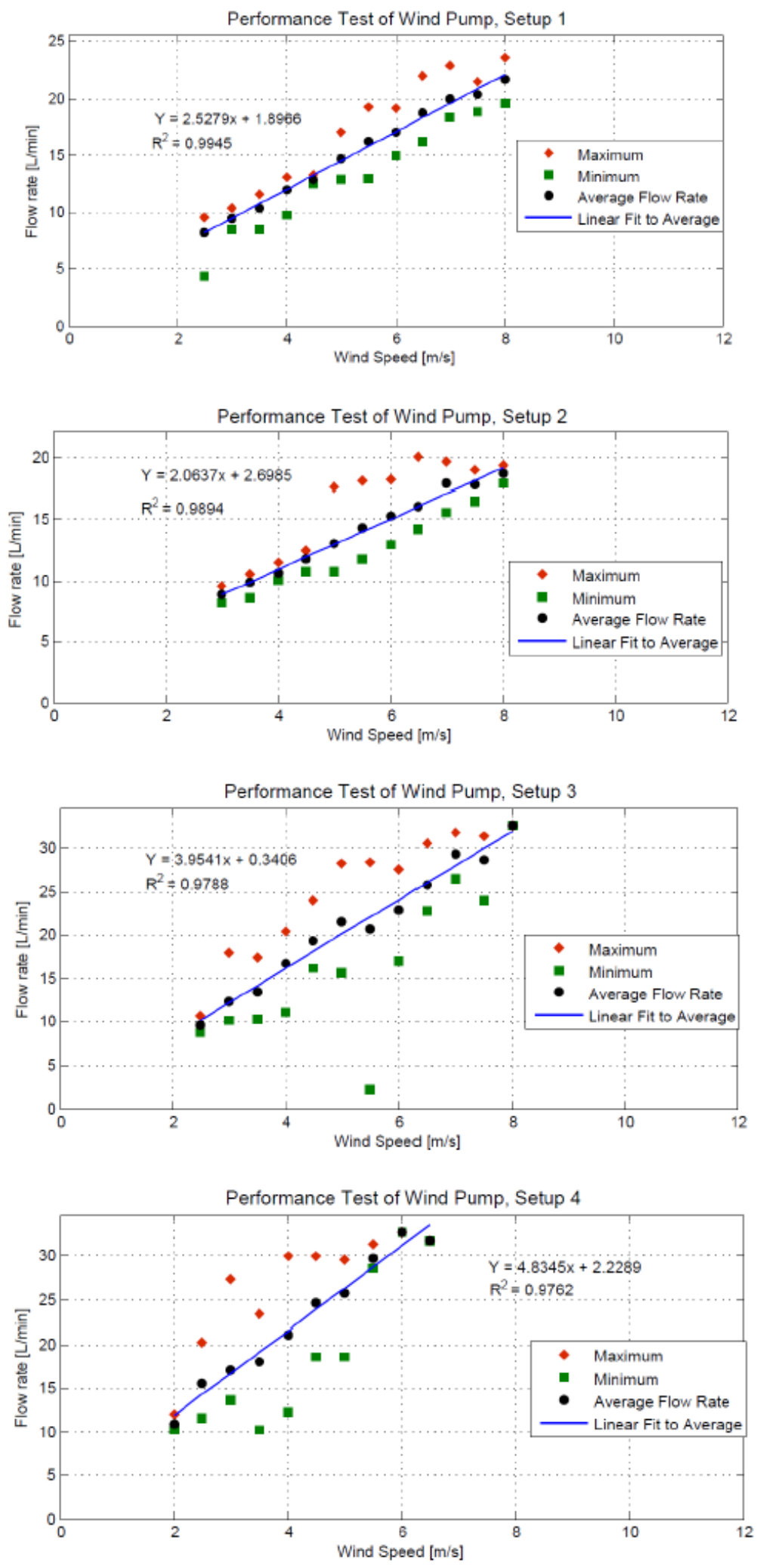

Figure 6. Measured flow rate versus the respective wind speed. 

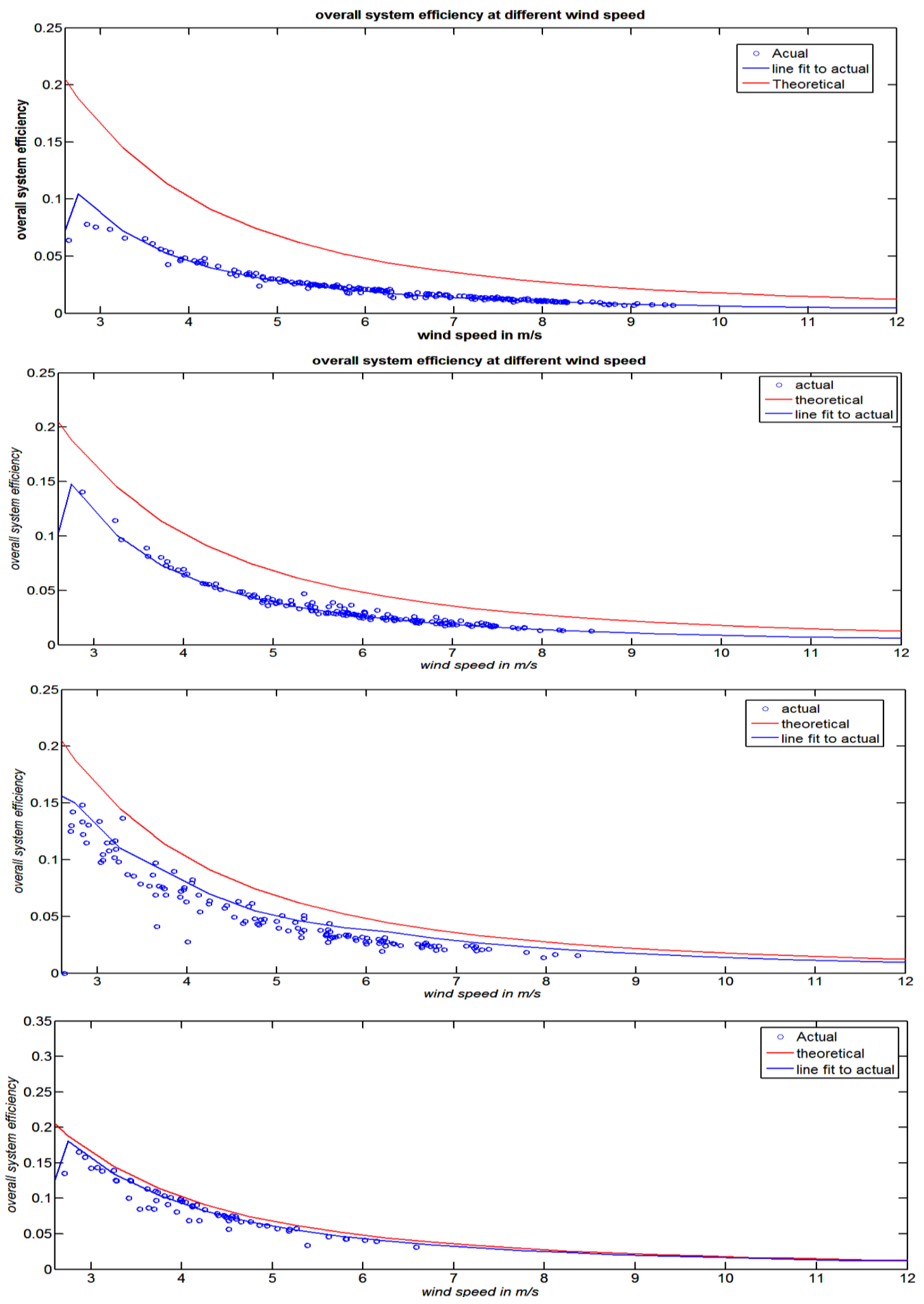

Figure 7. Overall system efficiency model results (theoretical) and measured values (actual), top to bottom Setups 1, 2, 3 and 4. 


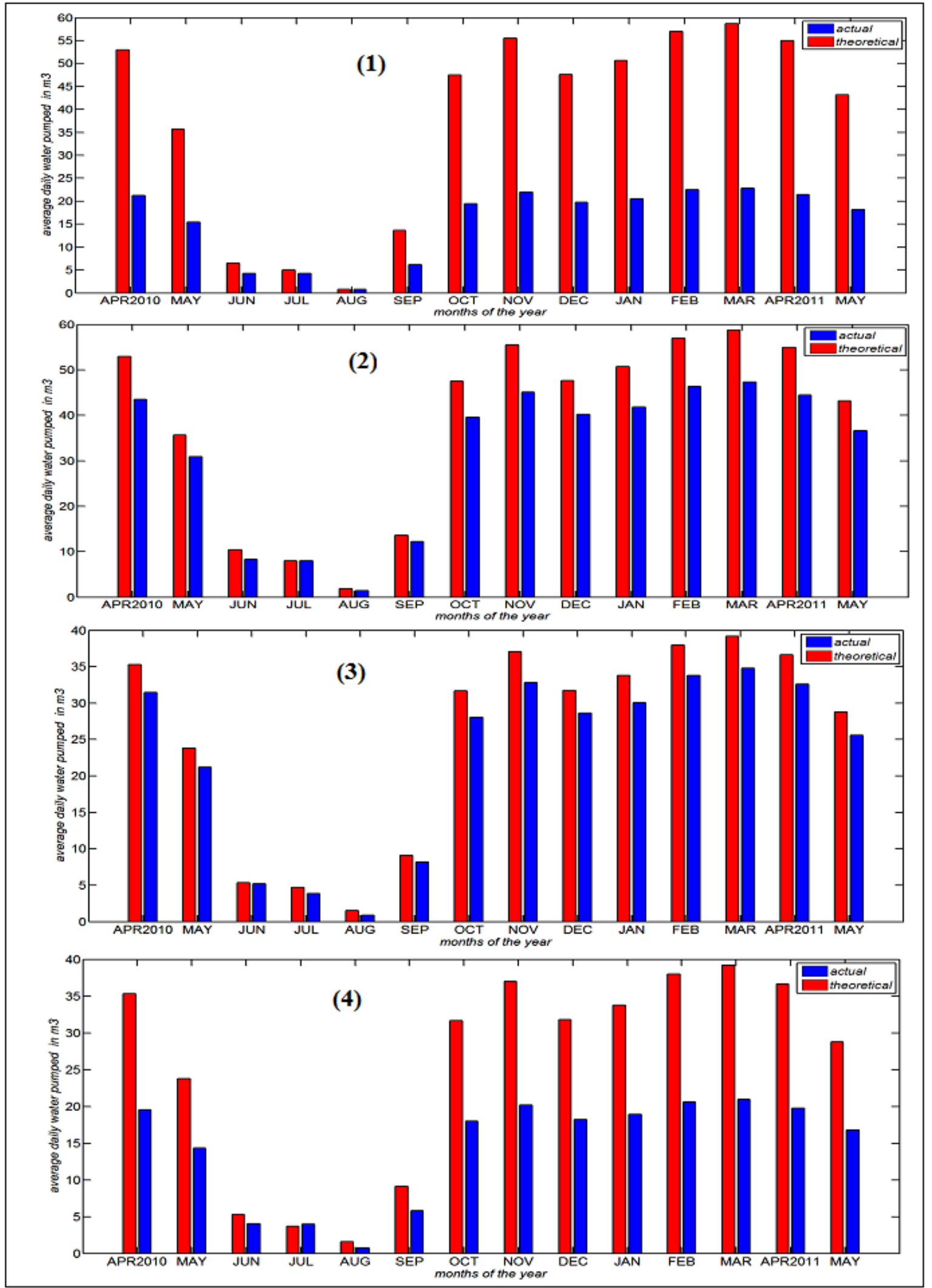

Figure 8. Daily average discharge, top to bottom Setups 1, 2, 3 and 4. 


\subsubsection{Daily water discharge}

Based on the actual measurement taken as representative data, prediction can be made for the one year wind data. Figure 8 shows the plots for the four setups. The figure shows that due to the difference in efficiency between the theoretical prediction and the actual measured value, the actual daily discharge is also lower than the prediction. The actual daily discharge during the rainy months is below $10 \mathrm{~m}^{3}$. During most of the year, the daily discharge for the $55 \mathrm{~mm}$ pump was $20 \mathrm{~m}^{3}$ and $19 \mathrm{~m}^{3}$ at $8 \mathrm{~m}$ and $12 \mathrm{~m}$ head, respectively. For the $70 \mathrm{~mm}$ pump the daily discharge was $41 \mathrm{~m}^{3}$ and $30 \mathrm{~m}^{3}$ at $8 \mathrm{~m}$ and $12 \mathrm{~m}$ head.

\section{CONCLUSIONS}

The theoretical model to estimate the water discharge of the wind pump was based on the combined efficiency of the rotor and the reciprocating pump. Values for the parameters such as rotor power coefficient, $\mathrm{C}_{\mathrm{p}}$, the combined transmission and pump efficiency, $\eta_{(\mathrm{t}, \mathrm{p})}$ and the constant, $K_{o}$ were assumed to estimate the performance of the wind pump. Based on the model and one year wind speed data the estimated daily discharge during the dry season was found to be around $50 \mathrm{~m}^{3}$ and $30 \mathrm{~m}^{3}$ at $8 \mathrm{~m}$ and $12 \mathrm{~m}$ head, respectively.

Experiments conducted using pump sizes of $55 \mathrm{~mm}$ and $70 \mathrm{~mm}$ at two different heads indicate that the theoretical model overestimated the daily discharge. With the $55 \mathrm{~mm}$ pump the measured daily discharge was 20 and $19 \mathrm{~m}^{3}$ at $8 \mathrm{~m}$ and $12 \mathrm{~m}$ head. With the $70 \mathrm{~mm}$ pump the measured daily discharge was $41 \mathrm{~m}^{3}$ and $30 \mathrm{~m}^{3}$ at $8 \mathrm{~m}$ and $12 \mathrm{~m}$ head, respectively. It can be concluded that the $70 \mathrm{~mm}$ pump has better performance and closer to the theoretical prediction. The overall conclusion is that the wind pump performance test was successful and the wind pump may be further tested in actual site conditions.

\section{ACKNOWLEDGMENTS}

The work reported here was sponsored by NARF project and MU - IUC program under Mekelle University. We would like to acknowledge the generous funding. We would like also to acknowledge funding from EnPe (NORAD's program for Energy and Petroleum) for M.Sc. students attached to the project. 


\section{REFERENCE}

Clark, R. N. 1995. Comparison of Two Mechanical Windmills for Pumping Water. Wind Power, American Wind Energy Association Annual Conference and Exhibition, Washington, D.C., 95:457-463,

Clark, R. N \& McCarty, J. W. 1990. Variable Stroke Pumping for Mechanical Windmill. Wind Power, Annual Conference and Exhibition of American Wind Energy Association, Washington, D.C., 90:217-221,

Hydrochina Corporation, 2012. Master Plan Report of Wind and Solar Energy in the Federal Democratic Republic of Ethiopia, Final version: p 21-81.

Mathew, S. 2006. Wind Energy: Fundamentals, Resource Analysis and Economics. Berlin Heidelberg, Germany, Springer-Verlag.

Mulu Bayray, Anwar Mustefa, Hailay Kiros, Asfafaw Haileslasie, Ftwi Yohannes, Petros Gebray, Gebre Gebretsadik, Solomon T/Michael, Mohammedsalih Abdelkadir, Mesele Hayelom, Ashenafi Kebedom, Ashenafi Atsbeha, Dawit Abay, Alemu Yemane, 2012. Assessment and Identification of Wind Resource for Rural Application in Geba Catchment. Proceedings of the NARF program workshop, Addis Ababa.

Mulu Bayray, Anwar Mustefa, Ftwi Yohannes, Hailay Kiros, Asfafaw Haileslasie, Petros Gebray, Mesele Hayelom, Addisu Dagne, 2013. Wind Energy Data Analysis and Resource Mapping of Geba Catchment, North Ethiopia. Wind Engineering, 37(4): 333346.

Mulugeta, Y \& Drake, F. 1996. Assessment of Solar and Wind Energy Resources in Ethiopia, Part II Wind Energy. Solar Energy, 57(4):323-334.

SWERA (Solar and Wind Energy Resource Assessment), 2007. Solar and Wind Energy Utilization and Project Development Scenarios. Final Report, Addis Ababa, Ethiopia, p $3.1-3.12$.

Van Meel, J. \& Smulders, P. 1989. Wind Pumping, A Hand Book. The World Bank, Washington, D.C, p 37-43. 